\title{
Searching for ways to switch on brown fat: are we getting warmer?
}

\author{
Andrew Whittle \\ Metabolic Research Laboratories, Institute of Metabolic Science, Addenbrooke's Hospital, University of Cambridge, Cambridge, UK \\ (Correspondence should be addressed to A Whittle; Email: ajw232@medschl.cam.ac.uk)
}

\begin{abstract}
Obesity rates are increasing alongside those of its co-morbidities, placing a huge strain on health systems across the globe. Evidence points to inappropriate levels of ectopic lipid accumulation outside of adipose tissue being a major factor in the progression of many of these diseases. Brown adipose tissue (BAT) has a huge capacity to remove lipids from the circulatory system to fuel thermogenesis. Multiple studies have now confirmed the existence of active BAT in adult humans, making strategies aimed at activating it a potential therapeutic option in obese subjects. In recent years, researchers working in murine models have found a wide range of endogenous molecules with specific roles regulating BAT. These findings place BAT firmly within the wider network of physiological regulation covering global metabolism. They also highlight the possibility of targeting thermogenesis in a safe and specific manner to remove potentially harmful lipids released from stressed or failing white adipose tissue in obese states.
\end{abstract}

Journal of Molecular Endocrinology (2012) 49, R79-R87

\section{Introduction}

Brown adipose tissue (BAT) is currently the focus of a global resurgence in scientific interest, owing to its now confirmed presence and functionality in humans. Its importance for energy balance in rodents has been known for decades, and, therefore, the suggestion has been put that it has potential as an anti-obesity strategy in humans. The problem is that previous attempts to target human BAT through the sympathetic nervous system (SNS) have proven unsafe. This review aims to draw attention to a range of molecules identified in past months that appear able to activate BAT via different and previously undescribed mechanisms. The research community should be encouraged that BAT is not an impossible target, and there are a range of imaginative strategies that might serve to enhance BAT function in a highly specific manner (Fig. 1).

\section{Why switch on brown fat in humans?}

It is now beyond debate that obesity is a burgeoning epidemic, caused primarily by a state of positive energy balance and characterised by the excess deposition of lipids in white adipose tissue (WAT) as well as ectopically in nonadipose tissues. The condition is strongly associated with hyperglycaemia, increased circulating triglycerides, insulin resistance and diabetes. These co-morbidities themselves increase the risk of other diseases, particularly those of the cardiovascular system. Amongst younger individuals, the rise in obesity rates is threatening to reverse the reduction seen in previous years in mortality from myocardial infarction, the leading cause of death across the globe (Allender et al. 2008, O'Flaherty et al. 2008, Vaartjes et al. 2011). Also, as the population ages, peripheral vascular disease, reno-vascular disease, cerebral vascular disease, and vascular dementia are also likely to become increasingly prevalent. If better approaches to tackle the spread of obesity are not implemented, we face further increases in these related health burdens.

It has been suggested that the increase in WAT volume is not in itself problematic but rather the crucial factor is the point at which a person reaches their maximum lipid storage capacity (Virtue \& Vidal-Puig 2008). This 'adipose expandability' hypothesis poses that when the maximal adipose capacity is reached (and the threshold differs hugely between individuals), a failure to buffer daily lipid fluxes results in ectopic fat deposition in heart, liver, muscle, pancreatic beta cells and the vasculature, a theory certainly supported by functional data from humans (McQuaid et al. 2011). 


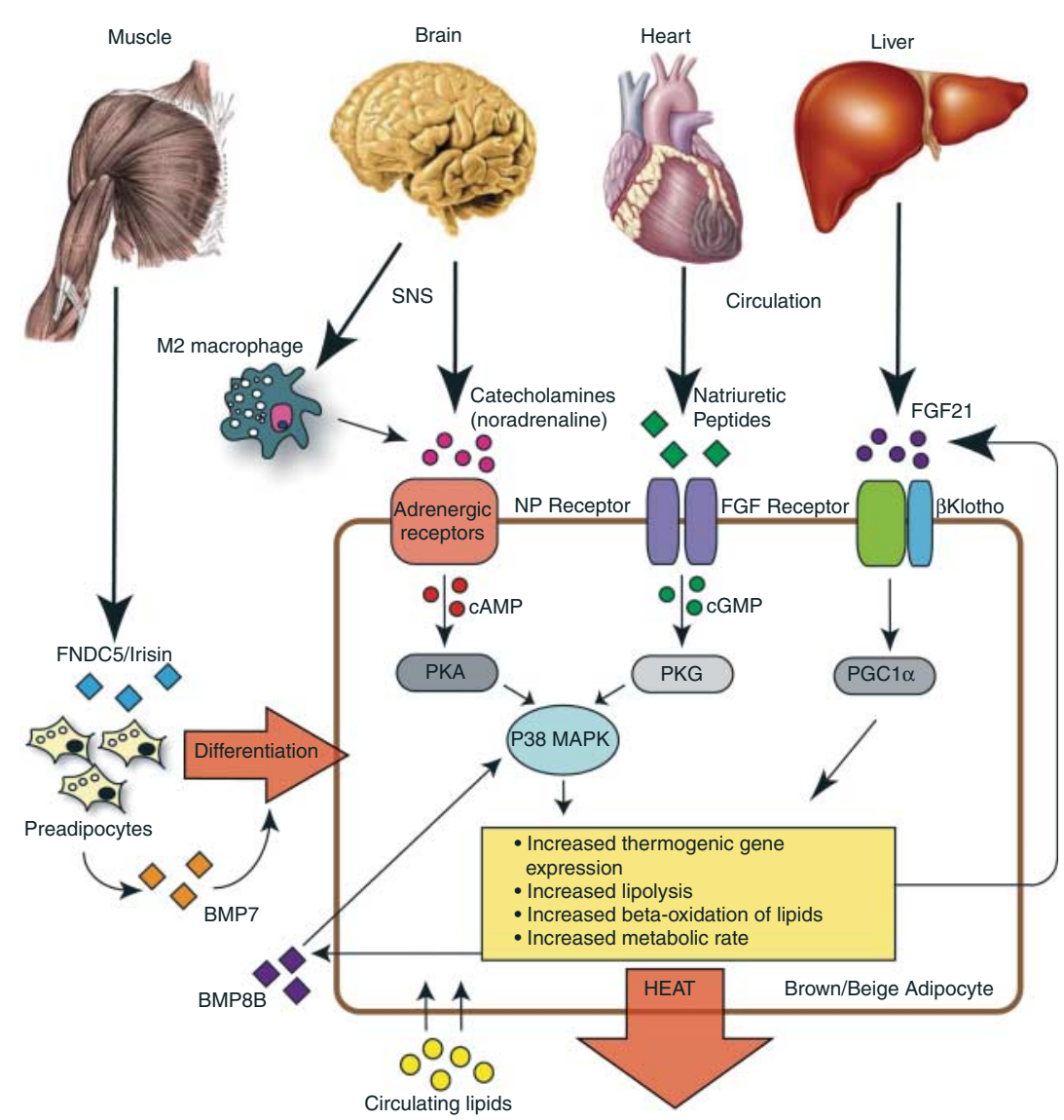

Figure 1 Overview of the range of molecules produced by different organs and cell types that can directly impact on BAT development and thermogenic function. Canonical regulation is via the SNS. Of particular interest is the fact that many of the recently characterised molecules signal through specific receptors to enhance the capacity of brown adipocytes to respond to adrenergic stimulation. The range of tissues that signal to BAT under a variety of physiological conditions indicates that BAT is an important component of global metabolic responses.

These non-adipose tissues are poorly adapted for fat storage and as such succumb to lipotoxic effects that lead to increased insulin resistance, inflammation and apoptosis (Virtue \& Vidal-Puig 2010). Obesity is also known to coincide with a state of chronic, low-level inflammation, and a pro-inflammatory switch in macrophage polarisation is typical of both the adipose tissue of obese, insulin-resistant humans and atherosclerotic plaques (Hansson 2005, Lumeng et al. 2007, Apovian et al. 2008, Thorp 2010).

A growing body of evidence supports the theory that exposure to increased levels of specific lipids can drive such perturbations. As such, lipids are becoming increasingly viewed as potent signalling molecules in their own right in the context of metabolic disease (Wymann \& Schneiter 2008). Palmitate for instance plays a key role in macrophage dysfunction and endoplasmic reticulum (ER) stress-mediated apoptosis (Li et al. 2009, Aflaki et al. 2011), and in obese mice, an increased lipid burden resulting from failed adipose tissue storage drives macrophage polarisation towards a pro-inflammatory state (Prieur et al. 2011). In the search for new ways to tackle the obesity epidemic, finding mechanisms for reducing circulating lipids beyond LDL-cholesterol seems an attractive primary target and one that is specifically encouraged by the European Atherosclerosis Society (Chapman et al. 2011).

\section{Brown adipose tissue}

BAT has evolved as an organ to ensure the maintenance of core body temperature in mammals. Where WAT stores lipids for the timely provision of energy, BAT burns them and uncouples their oxidation from ATP production through mitochondrial uncoupling protein 1 (UCP1), allowing the dissipation of energy as heat (Cannon \& Nedergaard 2004). When thermogenically active, the high rates of oxidative 
phosphorylation in BAT mean it requires large quantities of lipid and glucose, which it draws from both intracellular lipid stores (Ouellet et al. 2012) and directly from the circulation (Meyer et al. 2010, Bartelt et al. 2011). It is the metabolic nature of BAT that makes its application to human metabolic disease so attractive, as an organ with the potential to directly address the problems of positive energy balance, hyperglycaemia and hyperlipidaemia directly.

Interest in the application of BAT to human disease has snowballed in recent years thanks to advances in imaging techniques and stable glucose and lipid tracers. These tools have enabled numerous groups to detect active BAT depots in healthy individuals and are constantly improving in sensitivity (Cypess et al. 2009, Zingaretti et al. 2009, Lee et al. 2011, Ouellet et al. 2011, 2012, Yoneshiro et al. 2011, Mirbolooki et al. 2012). The amount of BAT detected varies greatly, but this is largely due to its detection being dependant on activity, which is highly responsive to environmental factors. Following the confirmation that its presence and regulation is intact in a large proportion of study subjects, it would seem logical for BAT, like all other organs, to exist to some extent in everyone. Extrapolating this idea leads inevitably to the idea that switching on this resident fat burning tissue could be useful in a clinical setting. In a previous review outlining the therapeutic usefulness of BAT from a bioenergetic perspective, it was estimated that when active, just a few grams of BAT had the potential to increase daily energy expenditure in humans by as much as 20\% (Cypess \& Kahn 2010). This is a purely theoretical assumption and is likely an overstatement of human BAT capacity but it does serve to highlight the immense metabolic capacity of brown adipocytes. Indirect calorimetry data from humans instead suggests that the figure is closer to 6\% (Yoneshiro et al. 2012) and in fact a more subtle increase in energy expenditure may be better for longterm weight loss strategies. Any large shift is likely to either drive a compensatory increase in food intake or a large drop in body weight, in turn reducing basal metabolic rate and negating the thermogenic activity. However, beyond BAT's potential for redressing positive energy balance, it is likely that its capacity to remove lipids from the circulatory system will have benefits beyond just weight reduction in patients at increased risk of cardiovascular disease, diabetes and stroke.

\section{Physiological regulation of thermogenesis in BAT}

Physiological regulation of BAT occurs via the SNS and is primarily mediated through activation of $\beta 3$ adrenergic receptors expressed on brown adipocytes. Adrenergic stimulation of BAT increases intracellular cAMP and in turn activates protein kinase A (PKA). This mediates both the induction of thermogenic gene expression via downstream protein kinases and transcriptional regulators such as peroxisome proliferator-activated receptor gamma co-activators (PGCs). At the same time, it leads to the acute activation of enzymes required for the uptake, mobilisation and mitochondrial oxidation of lipids (Cannon \& Nedergaard 2004, Collins et al. 2010). A second important regulator of BAT function that is equally well characterised is thyroid hormone, which works in synergy with the SNS to enhance the stimulatory effects of noradrenaline (Silva 1995).

These regulatory mechanisms also obviously exist in humans, and conditions such as phaeochromocytoma (a catecholamine-producing tumour of the adrenal gland; Lean et al. 1986) and chronic hyperthyroidism (Skarulis et al. 2009) indicate that increased stimulation through either of them can serve to significantly increase the amount and thermogenic activity of BAT, as is routinely observed in rodents. However, the adrenergic and thyroid axes regulate swathes of global physiology, controlling not just metabolism but numerous organs and cellular processes. Their validity as pharmacological targets to increase thermogenesis are supported by the effectiveness of drugs such as ephedrine and sibutramine at increasing sympathetic nerve activity to increase metabolic rate and reduce body weight (Finer et al. 2000). Unfortunately, these drug-based strategies also result in the promiscuous over-stimulation of adrenergic receptors expressed in the cardiovascular system (Haller \& Benowitz 2000, Torp-Pedersen et al. 2007). As such, unacceptable increases to the risk of stroke and heart attack have precluded their continued use in humans. In addition, recent evidence from humans suggests that ephedrine's energy expending effects are not driven via increased BAT stimulation but by some other less specific metabolic activation (Cypess et al. 2012).

\section{The search for new ways to activate BAT}

Given the 'proof of principle' of the activation of BAT in humans, there has been a surge in research to understand in detail its regulation, with the aim of finding safe and effective ways to increase thermogenesis. The result has been that over recent years, a number of molecules have come to light that possess the ability to regulate either the differentiation and the expansion of BAT and/or its acute thermogenic activity. Two of the most interesting characteristics of these molecules are that they exist under normal physiological conditions and work not through the direct activation of adrenergic or thyroid receptors but 
instead target-specific aspects of brown adipocyte biology. In this sense, they are perhaps less likely to cause cytotoxicity or have detrimental effects in other tissues. In addition, it has been a surprising revelation that a large number of peripheral organs and cell types produce molecules with distinct effects on BAT. This has updated the view of BAT being an isolated tissue with a single role and instead placed it firmly within a regulatory network of broader physiological responses.

\section{BAT regulatory molecules produced by other organs}

\section{Heart}

The maintenance of thermogenesis in BAT depends fundamentally on an abundant supply of nutrients and oxygen and therefore on cardiac output. Following cold exposure, the classical environmental driver of thermogenesis, a number of changes occur in the cardiovascular system including hypertension and cardiac hypertrophy (Sun 2010). Natriuretic peptides (NPs) are hormones produced in the heart that traditionally act on the renal system to maintain fluid homoeostasis. NPs increase cyclic GMP levels to activate cGMPdependant PKG, which shares homology with PKA in terms of its potential substrates (Misono 2011). Lipolysis in adipose tissue following adrenergic stimulation was thought to be solely dependant on cAMP levels, but it has been demonstrated that in white adipocytes, increased cGMP levels following NP treatment can also have a potent lipolytic effect (Lafontan et al. 2008). More recent work has shown that the same is true in brown adipocytes, where NPs can enhance the adrenergic activation of the intracellular kinases important for stimulating lipid oxidation and inducing thermogenic machinery (Bordicchia et al. 2012). This raises the possibility of achieving greater activation of BAT from an existing level of adrenergic stimulation, thus avoiding off-target effects associated with increasing sympathetic nervous tone itself (Whittle \& Vidal-Puig 2012). Treating mice with NP resulted in increased energy expenditure and an induction of thermogenic genes in BAT, but given the role of NP in the kidney, dosing obese humans with NP itself is unlikely to be a viable therapeutic approach.

\section{Muscle}

During exercise, skeletal muscle becomes a highly metabolically active organ, disposing of carbohydrates and lipids just like BAT, but over recent years, it has also become recognised as an important secretory organ. It is clear that the production of many of these myokines increases during/following exercise, resulting in positive metabolic effects in other organs, including adipose tissue. The full scope and potential impact of theses findings has been the subject of a detailed review (Pedersen \& Febbraio 2012), but one specific myokine, irisin, has been implicated directly in the regulation of BAT.

Exercise increases Ucp1 expression in BAT, improves vascular function and insulin sensitivity, increases the metabolic response to cold and improves the ability of pre-adipocytes from BAT to differentiate into mature brown adipocytes (Seebacher \& Glanville 2010, Xu et al. 2011). No clear mechanism had been suggested for how these BAT effects were mediated but the characterisation of irisin has presented a potential candidate. Bostrom et al. (2012) show that exercise also induces a 'browning' of traditional white fat depots and that this effect can be enhanced by PGCl $\alpha$ over-expression in muscle. They examined candidate PGC1 $\alpha$-dependant myokines and found that irisin (a cleavage product of FNDC5) was able to induce brown adipocyte gene expression in cultured adipocytes from WAT, via activation of peroxisome proliferator-activated receptor $\alpha(\operatorname{PPAR} \alpha)$. The group also demonstrate that viral over-expression of FNDC5 improves the metabolic profile of mice with diet-induced obesity and that the browning effect of exercise on WAT is impaired by injecting antibodies to FNDC5.

Exercise has a clear positive effect on multiple facets of metabolic health but is an activity often precluded by mechanical limitations in morbidly obese individuals. Therefore, identification of the molecular mechanisms driving these beneficial effects might be of particular import. Irisin appears to increase the number of cells within WAT that have the potential to dispose of excess lipids. The key question now is whether exploiting this molecular mechanism in obese patients would drive new 'beige' cells to undertake this task, or whether this oxidative function is dependant on other changes induced by exercise itself. There is certainly increasing evidence that multiple factors can enhance the propensity for pre-adipocytes to become 'beige adipocytes', which are different in lineage from classical BAT in mice, and recently it has been suggested that depots in humans identified as BAT have expression profiles more similar to murine beige adipocytes (Wu et al. 2012). Unfortunately, there are to date very little data to allow us to infer the metabolic relevance of these beige cells from a bioenergetics perspective.

\section{Liver}

Within the field of research into metabolic disease, great interest surrounds fibroblast growth factor 21 (FGF21). This follows the finding that transgenic mice overexpressing FGF21 in liver exhibit resistance to dietinduced obesity, alongside markedly enhanced insulin 
sensitivity and reduced circulating triglycerides (Kharitonenkov et al. 2005). Further studies have demonstrated that treatment of obese mice with FGF21 is sufficient to reduce bodyweight by $20 \%$ and that this negative energy balance is brought about almost entirely by increased energy expenditure (Coskun et al. 2008). More recent work by Hondares et al. (2010) found that FGF21 secretion by liver is an important component of the neonatal response to the cold environmental stress of life outside the womb. The researchers demonstrated that hepatic FGF21 production increased in response to initial suckling, dependant on PPAR $\alpha$. Treatment of neonates with additional FGF21 greatly enhanced the activation of thermogenic machinery in BAT and this response was also seen in treated brown adipocytes. The same group has since shown that FGF21 is also produced by BAT in response to thermogenic activation and that following cold exposure BAT becomes the major contributor to serum levels of the peptide (Hondares et al. 2011). This finding suggests that BAT is an endocrine organ in its own right, which is able to positively regulate its own activity and potentially increase FGF21 signalling in other metabolic tissues. The fact that FGF21 requires a specific membrane receptor, betaKlotho, to facilitate its interaction with traditional FGF receptors might also increase its potential as a therapeutic target (Ogawa et al. 2007).

\section{Brown adipose tissue}

In addition to FGF21 production, there are other BAT-intrinsic molecular mechanisms, which might be exploited to enhance the capacity for thermogenesis in humans by increasing the pool of BAT in any given individual. Molecules such as bone morphogenetic protein 7 (BMP7) and the transcription factor PR domain containing 16 (PRDM16) have become recognised as key factors necessary for driving the differentiation of adipocyte precursors to a brown cell fate (Seale $e t$ al. 2008, Tseng et al. 2008). Traditional brown adipocytes originate from a myocyte lineage and require PRDM16 to suppress myogenic gene expression and allow induction of the brown adipogenic programme. BMP7 is expressed early in brown fat development as a secreted factor necessary for the formation of traditional BAT depots. BMP7 induces expression of PRDM16 as well as PGCl $\alpha$ and its secretory nature makes its signalling pathway an obvious candidate for therapeutic application. The amount of BAT varies significantly between individuals and is generally harder to detect with increasing bodyweight, perhaps partly due to the insulating capacity of WAT and a reduced demand for heat production (Pfannenberg et al. 2010). In any case, the fact that those in greatest need of BAT likely possess less of it means that the ability to differentiate a greater number of mature brown adipocytes from precursor cells might be a very useful tool. Whether manipulation of these molecular mechanisms has the potential, like irisin, to increase the number of 'beige' cells in WAT depots remains questionable, as these cells do not stem from the same lineage as traditional brown adipocytes (Petrovic et al. 2010, Wu et al. 2012). Another BMP, BMP8B, has more recently come to light that functions to increase thermogenesis through a completely different mechanism. This secreted protein functions both in BAT, to enhance the response to adrenergic stimulation, and in brain, to specifically increase the level of sympathetic activation of thermogenesis (Whittle $e t$ al. 2012). Doubtless, as we continue to examine BAT in more detail, we will learn more about the endogenous mechanisms that regulate its function and interaction with global physiological responses.

\section{Central regulation of BAT}

The SNS regulation of BAT is coordinated in the hypothalamus, where information on environmental and nutritional changes affects the appropriate activation of thermogenesis. Thyroid hormone, a key regulator of BAT, has recently been shown to exert a substantial portion of its thermogenic effect by regulating AMP-activated protein kinase activity in the ventromedial hypothalamus (Lopez et al. 2010). In fact, the ability of a large number of hormones and circulating factors to activate BAT via hypothalamic mechanisms has been the focus of a previous review (Whittle et al. 2011). This topic will not be discussed here, but it is important to acknowledge that multiple endogenous mechanisms exist with the capacity to switch on thermogenesis without directly signalling to brown adipocytes. This includes gut hormones and adipokines such as leptin.

\section{Macrophages}

Perhaps the most surprising of the emerging family of BAT regulators are macrophages. Technically, these do not produce a novel type of molecule, but their mechanism of interaction with BAT has forced researchers to question the previous dogma surrounding adrenergic regulation of thermogenesis. As discussed earlier in this review, macrophage polarisation has become an area of particular focus in metabolic disease. Nguyen et al. (2011) noticed that markers of M2 or anti-inflammatory macrophage polarisation were up-regulated in BAT and WAT following cold exposure. Mice that lacked the ability to polarise macrophages in this manner due to the absence of interleukin 4 (IL4) signalling were also unable to maintain their body 
temperature in the cold. Conversely, treating mice with IL4 resulted in more of these M2 macrophages in BAT and an increase in energy expenditure. The authors propose that these macrophages themselves secrete catecholamines to sustain BAT activation. This is not unheard of; macrophages in lung secrete catecholamines as part of the immune response to acute tissue injury (Flierl et al. 2009), but the findings in BAT are intriguing because they place anti-inflammatory macrophages inside the normal regulatory loop of BAT physiology. This idea is extremely novel and still needs to be confirmed in other murine models and dissected in greater molecular detail in terms of its mechanism of action. It seems for instance that a large part of the effect may be driven by a role of these macrophages facilitating the prolonged efflux of lipids stored in WAT to fuel high rates of oxidation in BAT.

From these findings, it is tempting to question whether the switch towards inflammatory macrophage polarisation typical of obese states could be a contributing factor to weight gain - actively impairing BAT function and thus depressing energy expenditure. There is to date no evidence to suggest that inflammation causes obesity, but a pro-inflammatory milieu is certainly common in individuals who have already become obese. Perhaps the relevance of these finds is more pertinent for those trying to reverse obesity, whereby more inflammation is not so much of a driver of weight gain but an inhibitor of weight loss.

\section{Translation to human biology}

Current strategies to address obesity and its related diseases are failing, and unless new approaches are designed and implemented, the associated health burden will cripple economies across the globe. There is now substantial evidence that inappropriately high levels of lipid accumulation in organs outside of adipose tissue are an important factor driving much of the morbidity and mortality associated with obesity (Wymann \& Schneiter 2008, Unger et al. 2009). Therefore, given that its primary function is to burn lipids in an energetically wasteful process and the fact that historically it has been largely dismissed as metabolically irrelevant in humans, BAT constitutes something of an untapped resource. Its usefulness in human disease should of course be carefully considered; much of the work outlined in this review draws on evidence from murine models and caution must be exercised when translating the findings to humans. There is also huge variance between individuals concerning the amount of BAT activity that can be detected using current methods, and it may well be that the modern living environment (central heating and indoor work environments) removes much of the environmental stimulus for BAT activation (Johnson et al. 2011). However, there is almost certainly a correlation between factors that increase the risk of metabolic syndrome (insulin resistance, higher fat mass and increasing age) and reduced activity of BAT in human subjects (Pfannenberg et al. 2010, Ouellet et al. 2011). Whether this correlation indicates cause or consequence of obesity will likely be a matter of debate for years to come, but, in any case, it represents an opportunity. In people where chronic positive energy balance has led to increased risk of metabolic disease, there is a suggestion that BAT could be more active than it is.

\section{Designing new therapeutic approaches}

As BAT performs such a specialised role and one that opposes the goals of other tissues (energy wastage compared to energy conservation), it is perhaps reasonable to think that regulatory pathways have arisen that are extremely specific to this tissue. Therefore, if novel targets are sought to bring about changes to energy balance and lipid homoeostasis, an oxidative cellular mass that sits within a regulatory network of metabolic organs and has largely been discounted as a clinical resource may not be a bad place to start looking. The recent explosion of findings from murine studies is extremely encouraging, if only as a demonstration of the various options for further investigation. Beyond this, it is a success story emanating from the use of animal phenotyping to dissect poorly understood physiological processes and one that has begun to yield valuable results. The combination of molecules with roles restricted to BAT and thermogenic activation (PRDM16 and irisin) and those with the ability to bring about wider metabolic improvements in multiple tissues (FGF21) suggests that we may one day be able to tailor therapy to an individual's specific needs. While these findings need their relevance clarified in humans, it certainly seems that pharmacology has a few new targets to aim for.

Administering drugs that enhance the formation of beige cells is also an attractive mechanism to enhance the thermogenic capacity of an individual by expanding their pool of BAT. Mouse strains with higher thermogenic gene expression in WAT depots tend to be more resistant to obesity and insulin resistance than those with less (West et al. 1992, Guerra et al. 1998). However, the morphological manipulation of distinct tissue depots is a long way from becoming reality and would require years of extensive testing before safety concerns surrounding its use in humans could be satisfied. Yet some of those molecules that at first glance seem unlikely candidates for direct use as drugs (NPs for example) still serve to demonstrate that there may be 
mileage to improve earlier thermogenic approaches that were effective but unsafe. We know that increasing sympathetic nervous activation to BAT reduces body weight in humans and mice but cannot be done specifically enough in the former, as it detrimentally affects the cardiovascular system. Caution will also be required when deciding how potently to activate BAT, even if it can be done specifically. Active BAT requires increased blood supply and oxygen and cold-exposed mice become hypertensive and display cardiac hypertrophy. Likewise, cold temperatures worsen hypertension and risk of stroke in humans (Sun 2010). Some of these manifestations are likely to be part of the broader physiological response to cold, but still unnecessary BAT-driven cardiac stress will need to be avoided in obese individuals.

By continuing to search within the brown and beige adipocytes' molecular mechanisms, it is conceivable that we might find ways to leave classical thermogenic regulators such as the adrenergic axis untouched but improve BAT's response to existing levels of activation. Such approaches might allow us to make resident BAT depots get a little warmer.

\section{Declaration of interest}

The author declares that there is no conflict of interest that could be perceived as prejudicing the impartiality of the review reported.

\section{Funding}

A W works in the laboratory of Prof. Antonio Vidal-Puig and is supported by The MRC and BBSRC.

\section{References}

Aflaki E, Radovic B, Chandak PG, Kolb D, Eisenberg T, Ring J, Fertschai I, Uellen A, Wolinski H, Kohlwein SD et al. 2011 Triacylglycerol accumulation activates the mitochondrial apoptosis pathway in macrophages. Journal of Biological Chemistry 286 7418-7428. (doi:10.1074/jbc.M110.175703)

Allender S, Scarborough P, O'Flaherty M \& Capewell S 2008 Patterns of coronary heart disease mortality over the 20th century in England and Wales: possible plateaus in the rate of decline. $B M C$ Public Health 8 148. (doi:10.1186/1471-2458-8-148)

Apovian CM, Bigornia S, Mott M, Meyers MR, Ulloor J, Gagua M, McDonnell M, Hess D, Joseph L \& Gokce N 2008 Adipose macrophage infiltration is associated with insulin resistance and vascular endothelial dysfunction in obese subjects. Arteriosclerosis, Thrombosis, and Vascular Biology 28 1654-1659. (doi:10.1161/ ATVBAHA.108.170316)

Bartelt A, Bruns OT, Reimer R, Hohenberg H, Ittrich H, Peldschus K, Kaul MG, Tromsdorf UI, Weller H, Waurisch C et al. 2011 Brown adipose tissue activity controls triglyceride clearance. Nature Medicine 17 200-205. (doi:10.1038/nm.2297)

Bordicchia M, Liu D, Amri EZ, Ailhaud G, Dessi-Fulgheri P, Zhang C, Takahashi N, Sarzani R \& Collins S 2012 Cardiac natriuretic peptides act via p38 MAPK to induce the brown fat thermogenic program in mouse and human adipocytes. Journal of Clinical Investigation 122 1022-1036. (doi:10.1172/JCI59701)

Bostrom P, Wu J, Jedrychowski MP, Korde A, Ye L, Lo JC, Rasbach KA, Bostrom EA, Choi JH, Long JZ et al. 2012 A PGC1- $\alpha$-dependent myokine that drives brown-fat-like development of white fat and thermogenesis. Nature 481 463-468. (doi:10.1038/nature10777)

Cannon B \& Nedergaard J 2004 Brown adipose tissue: function and physiological significance. Physiological Reviews 84 277-359. (doi:10.1152/physrev.00015.2003)

Chapman MJ, Ginsberg HN, Amarenco P, Andreotti F, Boren J, Catapano AL, Descamps OS, Fisher E, Kovanen PT, Kuivenhoven JA et al. 2011 Triglyceride-rich lipoproteins and high-density lipoprotein cholesterol in patients at high risk of cardiovascular disease: evidence and guidance for management. European Heart Journal 32 1345-1361. (doi:10.1093/eurheartj/ehr112)

Collins S, Yehuda-Shnaidman E \& Wang H 2010 Positive and negative control of Ucpl gene transcription and the role of $\beta$-adrenergic signaling networks. International Journal of Obesity 34 (Suppl 1) S28-S33. (doi:10.1038/ijo.2010.180)

Coskun T, Bina HA, Schneider MA, Dunbar JD, Hu CC, Chen Y, Moller DE \& Kharitonenkov A 2008 Fibroblast growth factor 21 corrects obesity in mice. Endocrinology 149 6018-6027. (doi:10. $1210 /$ en.2008-0816)

Cypess AM \& Kahn CR 2010 Brown fat as a therapy for obesity and diabetes. Current Opinion in Endocrinology, Diabetes, and Obesity 17 143-149. (doi:10.1097/MED.0b013e328337a81f)

Cypess AM, Lehman S, Williams G, Tal I, Rodman D, Goldfine AB, Kuo FC, Palmer EL, Tseng YH, Doria A et al. 2009 Identification and importance of brown adipose tissue in adult humans. New England Journal of Medicine 360 1509-1517. (doi:10.1056/NEJMoa0810780)

Cypess AM, Chen YC, Sze C, Wang K, English J, Chan O, Holman AR, Tal I, Palmer MR, Kolodny GM et al. 2012 Cold but not sympathomimetics activates human brown adipose tissue in vivo. PNAS 109 10001-10005. (doi:10.1073/pnas.1207911109)

Finer N, Bloom SR, Frost GS, Banks LM \& Griffiths J 2000 Sibutramine is effective for weight loss and diabetic control in obesity with type 2 diabetes: a randomised, double-blind, placebo-controlled study. Diabetes, Obesity E Metabolism 2 105-112. (doi:10.1046/j.1463-1326. 2000.00071.x)

Flierl MA, Rittirsch D, Nadeau BA, Sarma JV, Day DE, Lentsch AB, Huber-Lang MS \& Ward PA 2009 Upregulation of phagocytederived catecholamines augments the acute inflammatory response. PLoS ONE 4 e4414. (doi:10.1371/journal.pone.0004414)

Guerra C, Koza RA, Yamashita H, Walsh K \& Kozak LP 1998 Emergence of brown adipocytes in white fat in mice is under genetic control. Effects on body weight and adiposity. Journal of Clinical Investigation 102 412-420. (doi:10.1172/JCI3155)

Haller CA \& Benowitz NL 2000 Adverse cardiovascular and central nervous system events associated with dietary supplements containing ephedra alkaloids. New England Journal of Medicine 343 1833-1838. (doi:10.1056/NEJM200012213432502)

Hansson GK 2005 Inflammation, atherosclerosis, and coronary artery disease. New England Journal of Medicine 352 1685-1695. (doi:10.1056/NEJMra043430)

Hondares E, Rosell M, Gonzalez FJ, Giralt M, Iglesias R \& Villarroya F 2010 Hepatic FGF21 expression is induced at birth via PPAR $\alpha$ in response to milk intake and contributes to thermogenic activation of neonatal brown fat. Cell Metabolism 11 206-212. (doi:10.1016/ j.cmet.2010.02.001)

Hondares E, Iglesias R, Giralt A, Gonzalez FJ, Giralt M, Mampel T \& Villarroya F 2011 Thermogenic activation induces FGF21 expression and release in brown adipose tissue. Journal of Biological Chemistry 286 12983-12990. (doi:10.1074/jbc.M110.215889)

Johnson F, Mavroggiani A, Ucci M, Vidal-Puig A \& Wardle J 2011 Could increased time spent in a thermal comfort zone contribute to population increases in obesity? Obesity Reviews 12 543-551. (doi:10.1111/j.1467-789X.2010.00851.x) 
Kharitonenkov A, Shiyanova TL, Koester A, Ford AM, Micanovic R, Galbreath EJ, Sandusky GE, Hammond LJ, Moyers JS, Owens RA et al. 2005 FGF-21 as a novel metabolic regulator. Journal of Clinical Investigation 115 1627-1635. (doi:10.1172/JCI23606)

Lafontan M, Moro C, Berlan M, Crampes F, Sengenes C \& Galitzky J 2008 Control of lipolysis by natriuretic peptides and cyclic GMP. Trends in Endocrinology and Metabolism 19 130-137. (doi:10.1016/j. tem.2007.11.006)

Lean ME, James WP, Jennings G \& Trayhurn P 1986 Brown adipose tissue in patients with phaeochromocytoma. International Journal of Obesity 10 219-227.

Lee P, Ho KK \& Greenfield JR 2011 Hot fat in a cool man: infrared thermography and brown adipose tissue. Diabetes, Obesity and Metabolism 13 92-93. (doi:10.1111/j.1463-1326.2010.01318.x)

Li S, Sun Y, Liang CP, Thorp EB, Han S, Jehle AW, Saraswathi V, Pridgen B, Kanter JE, Li R et al. 2009 Defective phagocytosis of apoptotic cells by macrophages in atherosclerotic lesions of ob/ob mice and reversal by a fish oil diet. Circulation Research 105 1072-1082. (doi:10.1161/CIRCRESAHA.109.199570)

Lopez M, Varela L, Vazquez MJ, Rodriguez-Cuenca S, Gonzalez CR, Velagapudi VR, Morgan DA, Schoenmakers E, Agassandian K, Lage R et al. 2010 Hypothalamic AMPK and fatty acid metabolism mediate thyroid regulation of energy balance. Nature Medicine $\mathbf{1 6}$ 1001-1008. (doi:10.1038/nm.2207)

Lumeng CN, Bodzin JL \& Saltiel AR 2007 Obesity induces a phenotypic switch in adipose tissue macrophage polarization. Journal of Clinical Investigation 117 175-184. (doi:10.1172/JCI29881)

McQuaid SE, Hodson L, Neville MJ, Dennis AL, Cheeseman J, Humphreys SM, Ruge T, Gilbert M, Fielding BA, Frayn KN et al. 2011 Downregulation of adipose tissue fatty acid trafficking in obesity: a driver for ectopic fat deposition? Diabetes 60 47-55. (doi:10.2337/db10-0867)

Meyer CW, Willershauser M, Jastroch M, Rourke BC, Fromme T, Oelkrug R, Heldmaier G \& Klingenspor M 2010 Adaptive thermogenesis and thermal conductance in wild-type and UCP1-KO mice. American Journal of Physiology. Regulatory, Integrative and Comparative Physiology 299 R1396-R1406. (doi:10.1152/ajpregu. 00021.2009)

Mirbolooki MR, Constantinescu CC, Pan ML \& Mukherjee J 2012 Quantitative assessment of brown adipose tissue metabolic activity and volume using 18F-FDG PET/CT and $\beta 3$-adrenergic receptor activation. EJNMMI Research 1 30. (doi:10.1186/2191-219X-1-30)

Misono KS 2011 Natriuretic peptides and their receptors. FEBS Journal 278 1791. (doi:10.1111/j.1742-4658.2011.08114.x)

Nguyen KD, Qiu Y, Cui X, Goh YP, Mwangi J, David T, Mukundan L, Brombacher F, Locksley RM \& Chawla A 2011 Alternatively activated macrophages produce catecholamines to sustain adaptive thermogenesis. Nature 480 104-108. (doi:10.1038/nature10653)

O'Flaherty M, Ford E, Allender S, Scarborough P \& Capewell S 2008 Coronary heart disease trends in England and Wales from 1984 to 2004: concealed levelling of mortality rates among young adults. Heart 94 178-181. (doi:10.1136/hrt.2007.118323)

Ogawa Y, Kurosu H, Yamamoto M, Nandi A, Rosenblatt KP, Goetz R, Eliseenkova AV, Mohammadi M \& Kuro-o M 2007 BetaKlotho is required for metabolic activity of fibroblast growth factor 21. PNAS 104 7432-7437. (doi:10.1073/pnas.0701600104)

Ouellet V, Routhier-Labadie A, Bellemare W, Lakhal-Chaieb L, Turcotte E, Carpentier AC \& Richard D 2011 Outdoor temperature, age, sex, body mass index, and diabetic status determine the prevalence, mass, and glucose-uptake activity of 18F-FDG-detected BAT in humans. Journal of Clinical Endocrinology and Metabolism 96 192-199. (doi:10.1210/jc.2010-0989)

Ouellet V, Labbe SM, Blondin DP, Phoenix S, Guerin B, Haman F, Turcotte EE, Richard D \& Carpentier AC 2012 Brown adipose tissue oxidative metabolism contributes to energy expenditure during acute cold exposure in humans. Journal of Clinical Investigation 122 545-552. (doi:10.1172/JCI60433)
Pedersen BK \& Febbraio MA 2012 Muscles, exercise and obesity: skeletal muscle as a secretory organ. Nature Reviews Endocrinology 8 457-465. (doi:10.1038/nrendo.2012.49)

Petrovic N, Walden TB, Shabalina IG, Timmons JA, Cannon B \& Nedergaard J 2010 Chronic peroxisome proliferator-activated receptor $\gamma(\operatorname{PPAR} \gamma)$ activation of epididymally derived white adipocyte cultures reveals a population of thermogenically competent, UCP1-containing adipocytes molecularly distinct from classic brown adipocytes. Journal of Biological Chemistry 285 7153-7164. (doi:10.1074/jbc.M109.053942)

Pfannenberg C, Werner MK, Ripkens S, Stef I, Deckert A, Schmadl M, Reimold M, Haring HU, Claussen CD \& Stefan N 2010 Impact of age on the relationships of brown adipose tissue with sex and adiposity in humans. Diabetes 59 1789-1793. (doi:10.2337/ db10-0004)

Prieur X, Mok CY, Velagapudi VR, Nunez V, Fuentes L, Montaner D, Ishikawa K, Camacho A, Barbarroja N, O'Rahilly S et al. 2011 Differential lipid partitioning between adipocytes and tissue macrophages modulates macrophage lipotoxicity and M2/M1 polarization in obese mice. Diabetes 60 797-809. (doi:10.2337/ db10-0705)

Seale P, Bjork B, Yang W, Kajimura S, Chin S, Kuang S, Scime A, Devarakonda S, Conroe HM, Erdjument-Bromage H et al. 2008 PRDM16 controls a brown fat/skeletal muscle switch. Nature $\mathbf{4 5 4}$ 961-967. (doi:10.1038/nature07182)

Seebacher F \& Glanville EJ 2010 Low levels of physical activity increase metabolic responsiveness to cold in a rat (Rattus fuscipes). PLoS ONE 5 e13022. (doi:10.1371/journal.pone.0013022)

Silva JE 1995 Thyroid hormone control of thermogenesis and energy balance. Thyroid 5 481-492. (doi:10.1089/thy.1995.5.481)

Skarulis MC, Celi FS, Mueller E, Zemskova M, Malek R, Hugendubler L, Cochran C, Solomon J, Chen C \& Gorden P 2009 Thyroid hormone induced brown adipose tissue and amelioration of diabetes in a patient with extreme insulin resistance. Journal of Clinical Endocrinology and Metabolism 95 256-262. (doi:10.1210/jc. 2009-0543)

Sun Z 2010 Cardiovascular responses to cold exposure. Frontiers in Bioscience: a Journal and Virtual Library 2 495-503. (doi:10.2741/ e108)

Thorp EB 2010 Mechanisms of failed apoptotic cell clearance by phagocyte subsets in cardiovascular disease. Apoptosis 15 1124-1136. (doi:10.1007/s10495-010-0516-6)

Torp-Pedersen C, Caterson I, Coutinho W, Finer N, Van Gaal L, Maggioni A, Sharma A, Brisco W, Deaton R, Shepherd G et al. 2007 Cardiovascular responses to weight management and sibutramine in high-risk subjects: an analysis from the SCOUT trial. European Heart Journal 28 2915-2923. (doi:10.1093/eurheartj/ehm217)

Tseng YH, Kokkotou E, Schulz TJ, Huang TL, Winnay JN, Taniguchi CM, Tran TT, Suzuki R, Espinoza DO, Yamamoto Y et al. 2008 New role of bone morphogenetic protein 7 in brown adipogenesis and energy expenditure. Nature 454 1000-1004. (doi:10.1038/nature07221)

Unger RH, Clark GO, Scherer PE \& Orci L 2009 Lipid homeostasis, lipotoxicity and the metabolic syndrome. Biochimica et Biophysica Acta 1801 209-214. (doi:10.1016/j.bbalip.2009.10.006)

Vaartjes I, O'Flaherty M, Grobbee DE, Bots ML \& Capewell S 2011 Coronary heart disease mortality trends in the Netherlands 1972-2007. Heart 97 569-573. (doi:10.1136/hrt.2010.206565)

Virtue S \& Vidal-Puig A 2008 It's not how fat you are, it's what you do with it that counts. PLoS Biology 6 e237. (doi:10.1371/journal.pbio. 0060237)

Virtue S \& Vidal-Puig A 2010 Adipose tissue expandability, lipotoxicity and the metabolic syndrome - an allostatic perspective. Biochimica et Biophysica Acta 1801 338-349. (doi:10.1016/j.bbalip.2009.12.006)

West DB, Boozer CN, Moody DL \& Atkinson RL 1992 Dietary obesity in nine inbred mouse strains. American Journal of Physiology 262 R1025-R1032. 
Whittle AJ \& Vidal-Puig A 2012 NPs - heart hormones that regulate brown fat? Journal of Clinical Investigation 122 804-807. (doi:10.1172/JCI62595)

Whittle AJ, Lopez M \& Vidal-Puig A 2011 Using brown adipose tissue to treat obesity - the central issue. Trends in Molecular Medicine $\mathbf{1 7}$ 405-411. (doi:10.1016/j.molmed.2011.04.001)

Whittle AJ, Carobbio S, Martins L, Slawik M, Hondares E, Vazquez MJ, Morgan D, Csikasz RI, Gallego R, Rodriguez-Cuenca S et al. 2012 BMP8B increases brown adipose tissue thermogenesis through both central and peripheral actions. Cell 149 871-885. (doi:10.1016/j. cell.2012.02.066)

Wu J, Bostrom P, Sparks LM, Ye L, Choi JH, Giang AH, Khandekar M, Virtanen KA, Nuutila P, Schaart G et al. 2012 Beige adipocytes are a distinct type of thermogenic fat cell in mouse and human. Cell 150 366-376. (doi:10.1016/j.cell.2012.05.016)

Wymann MP \& Schneiter R 2008 Lipid signalling in disease. Nature Reviews Molecular Cell Biology 9 162-176. (doi:10.1038/nrm2335)

Xu X, Ying Z, Cai M, Xu Z, Li Y, Jiang SY, Tzan K, Wang A, Parthasarathy S, He G et al. 2011 Exercise ameliorates high-fat diet-induced metabolic and vascular dysfunction, and increases adipocyte progenitor cell population in brown adipose tissue.
American Journal of Physiology. Regulatory, Integrative and Comparative Physiology 300 R1115-R1125. (doi:10.1152/ajpregu. 00806.2010)

Yoneshiro T, Aita S, Matsushita M, Kameya T, Nakada K, Kawai Y \& Saito M 2011 Brown adipose tissue, whole-body energy expenditure, and thermogenesis in healthy adult men. Obesity 19 13-16. (doi:10.1038/oby.2010.105)

Yoneshiro T, Aita S, Kawai Y, Iwanaga T \& Saito M 2012 Nonpungent capsaicin analogs (capsinoids) increase energy expenditure through the activation of brown adipose tissue in humans. American Journal of Clinical Nutrition 95 845-850. (doi:10.3945/ajcn.111. 018606)

Zingaretti MC, Crosta F, Vitali A, Guerrieri M, Frontini A, Cannon B, Nedergaard J \& Cinti S 2009 The presence of UCP1 demonstrates that metabolically active adipose tissue in the neck of adult humans truly represents brown adipose tissue. FASEB Journal 23 3113-3120. (doi:10.1096/fj.09-133546)

Received in final form 17 July 2012

Accepted 24 July 2012

Made available online as an Accepted Preprint 24 July 2012 